\title{
Catalytic gem-Difluoropropargylation Using Aryl and Alkenyl Boron Reagents
}

\section{Selected examples:}<smiles>Cc1ccccc1C(F)(F)C#C[In]</smiles>

$77 \%$ yield<smiles>N#CC#CC(F)(F)c1ccc(C#N)cc1</smiles>

$78 \%$ yield<smiles>FC(F)(C#CC(F)(F)c1cccc(-c2ccccc2)c1)c1ccccc1</smiles>

$58 \%$ yield<smiles>CCOC(=O)c1ccc(C(F)(F)C#C[InH2])cc1</smiles>

$84 \%$ yield<smiles>FC(F)(F)C#CC(F)(F)c1cccc2ccccc12</smiles>

$79 \%$ yield<smiles>O=[N+]([O-])c1cccc(C(F)(F)C#CC(F)(F)F)c1</smiles>

$67 \%$ yield<smiles>CC(=O)c1ccc(C(F)(F)C#CC(F)(F)F)cc1</smiles>

$90 \%$ yield<smiles>FC(F)c1ccc(C(F)(F)C#CC(F)(F)F)cc1</smiles>

$87 \%$ yield
Significance: The authors report the first palladium-catalyzed gem-difluoropropargylation of organoboron reagents using gem-difluoropropargyl bromides. A wide range of novel molecules with potential use as building blocks in organic synthesis were prepared. The reaction proceeds with high regioselectivity, broad substrate scope, and excellent functional group compatibility.
Comment: Whereas in previous reports special phosphine ligands with large bite angles or very bulky substituents needed to be applied, now a simple ligand $(\mathrm{o}-\mathrm{Tol})_{3} \mathrm{P}$ can be used. The latestage introduction of the fluoro substituents is suitable for applications in the synthesis of complex molecules. 